\title{
Robust Action Dynamics in Political Discourse ${ }^{1}$
}

\author{
Balázs Vedres \\ University of Oxford
}

How do politicians gain an upper hand in political discourse? Recent literature on framings in political discourse have re-directed attention from static models of issue ownership to more interactive models of strategic framing contests. This article proposes a robust action approach, and tests hypotheses about the dual repertoires of local action: First, we test for the presence of exploratory local action, when discourse positions are altered in response to positions by others, and second, we show evidence for the presence of role claim behavior, when a dominant discourse position is taken that silences others. Using the case of economic policy discourse in Hungary in 1997, we show how the "GDP growth" discourse position silenced opposition positions on the right, mostly built from stigmatizing frames. Discourse positions beyond the one built around growth did not silence alternative framings, but elicited discourse shifts. We coded 8632 utterances over 100 days of discourse into a two-mode network of speech acts and statements and used a two-mode blockmodeling approach to identify positions and frames. We used a pooled time series approach to test hypotheses of local action dynamics. We found evidence for both exploratory local action and role claim, while controlling for observed and unobserved heterogeneity at the actor level.

\section{Introduction}

How do politicians gain an upper hand in political discourse? Political discourse is an arena where power is maintained and generated (van Dijk 1993; Fairclough 2013; Thornborrow 2016), and this process can be understood as a framing contest (Cornelissen and Werner 2014; Dewulf et al. 2009; Kaplan 2008), where political actors dynamically adjust their behavior to respond to framings from their opponents (Krebs and Jackson 2007). In this article we adopt a relational robust-action perspective to discourse, as we argue that political actors engage in framing contests by two kinds of behaviors: First, they are interested in exploring the repertoires of their opponents, making them shift through their discursive positions and thus reveal the full repertoire of their framings (Leifer 1988; Steinberg 1999). Second, beyond exploration political actors are interested in gaining the upper hand in discourse by taking a position that their opponents seem to have no viable answer to (Koopmans and Olzak 2004; Nelson and Kinder 1996; Schröter and Taylor 2018). In other words, political actors engage in

\footnotetext{
${ }^{1}$ I am most indebted for Peter Csigo for collecting and coding newspaper articles. I am thankful for comments of Peter Bearman, Daniel Beunza, Ronald Breiger, Laszlo Bruszt, Zsolt Enyedi, Bruce Kogut, John Krinsky, John Mohr, David Stark, Duncan Watts, and Harrison White. I am grateful for the support by the Center for Organizational Innovation and the Institute for Social and Economic Research and Policy in providing a fellowship during the preparation of this manuscript.
} 
discourse with a behavioral portfolio similar to that of a boxer, with an exploratory dace around the opponent, looking for the opportunity to deliver a punch (Wacquant 1995).

As the political field shifted from class-based party politics to issue-based party politics over the past half century, the importance to understanding the dynamics of issue representation has become an important task (Green-Pedersen 2019). One perspective to understand the connection between parties and discourse is to think of issue ownership, and The relationship between parties and issues is dynamic and competitive (Meguid 2005; Sniderman and Theriault 2004), with challenger parties bringing about disruptive innovation in framings (De Vries and Hobolt 2020; Hobolt and Tilley 2016).

We rely on a rich literature in political and cultural sociology that re-constructs discourse as a symbolic network (Carley 1994; Foucault 1972; Mohr 1998), to understand relations of power in the political field (Benford 1993; Bourdieu 1991). Our key contribution is that we shift focus to robust action in discourse as relational drama (McFarland 2004), rather than adopting the more usual focus on the reception of political frames by the audience (De Sio and Weber 2014; Vasi et al. 2015): in our study discourse positions are both the dependent and independent variables (Snow 2004), as we aim to understand strategic interaction of political rivals (Krebs and Jackson 2007; Mische and Pattison 2000; Steinberg 1999).

Robust action perspectives carry a lot of promise to conceptualize political discourse, but some central concepts are difficult to operationalize, such as opaqueness, ambiguity, and seizing the moment (Ferraro, Etzion, and Gehman 2015; Padgett and Ansell 1993). We rely on the concept of local action ${ }^{2}$ (Leifer 1988) and symbolic network analytic methods to provide a clear operationalization for robust action in political discourse. We distinguish two modes of acting: local action, when actors explore role repertoires of adversaries, and role claim, when an actor attempts to occupy a dominant discourse position. We argue that this idea of local action is a fruitful way to combine a structural analysis of symbols and speech acts with a relational analysis of political organizations struggling for power (Emirbayer and Goodwin 1994; Erikson 2016).

Our empirical case is the economic policy discourse of consolidation in Hungary, over the spring of 1997. During this period government side political actors (and other expert and journalist discourse participants mostly on the left) shifted from defending austerity measures to an offensive built on the idea of GDP growth. With this they defeated a stigmatizing offensive launched by young Viktor Orban and the FIDESZ party, that recently veered to the right. Using a two-mode blockmodeling approach to identify discourse positions, we show that this innovation relied on the most multivocal position in the discourse, combining

\footnotetext{
${ }^{2}$ Eric Leifer originally labelled local action as robust action in his unpublished dissertation (Leifer 1983), and the two concepts are usually taken to refer to the same phenomenon (White 2008). We use local action as a specific conceptualization of robust action - a broader concept of pragmatic skill (Ferraro, Etzion, and Gehman 2015).
} 
several frames in a way, that silenced opposition positions. While all other government and opposition side positions had a clear answer in the discourse, and did not significantly reduce the probability of speaking, the position on GDP growth significantly reduced the probability of speaking, regardless of the identity of actor. In a fashion that paralleled the world economic policy stage (Schmelzer 2016), growth discourse in our case connected macroeconomic indicators with individual prosperity in a uniquely effective way $^{3}$.

We translate our textual corpus into a network, building from ties among statements (the elementary symbols in this article) that are made when a political actor uses two or more statements in the same speech act. Taking the resulting two-mode network of statements connected with speech acts, we use a two-mode blockmodeling approach to reveal frames and positions - clusters of structurally equivalent statements and speech acts. We then analyze the relational dynamics of using these positions to test hypotheses about the presence of a local action dynamic in the discourse. First we test a weak hypothesis that the prevalence of discourse positions significantly differ from expected in the relevant temporal window following other positions. Second, we test two stronger hypotheses about local action, using a pooled time series approach that makes actor-days the units of analysis: One about exploratory local action - the dance of actors around one another in the discourse, and another about role claim, when actors take a position with the intention to silence others.

\section{Network approaches to discourse}

One conceptual goal is to find and establish bridges between the symbolic regularities of discourse and the dynamics of relations among political actors, as they struggle to dominate the agenda in the public sphere. We follow the fundamental duality of analyzing discourse as a system of representation, and as an arena of interaction (Dewulf et al. 2009; Gonos 1977). Analytically, cultural and social relations are to be mapped separately, but conceptually, the dimensions of meaning and agency should be joined together (Emirbayer and Goodwin 1994). Thus we first discuss perspectives of understanding symbolic structures (the structure of representation), and then perspectives on social relations in discourse (the structure of interactions).

We argue that symbolic regularities can be best conceptualized and measured by taking a network approach to symbolic elements. Network analytic approaches to discourse dynamics have offered unique insight into the evolution of institutions and broader cultural trends (Bail 2012; Carley 1994; Mohr 1994, 1998). Discourse network approaches maintain an analytic separation of the network dimension of symbols and the network dimension of actors (Fuhse 2016; Leifeld 2017).

\footnotetext{
${ }^{3}$ While it is reasonable to assume that GDP growth discourse was adopted from a globally connected expert and policy field, we nevertheless take it as an innovation that this discourse position was applied as bridging of frames locally (Snow et al. 1986; Werner and Cornelissen 2014).
} 
Our understanding of discourse as a network system builds from Michel Foucault's historical discourse analysis (Foucault 1972): a network conceptualization of discourse that predates quantitative formulation. Foucault proposes to think of discourse as a field composed of statements. He asserts that the aim of discourse analysis is to describe the principles of the dispersion of statements in the field of the discourse. The meaning of a statement derives from the associated field around it as it emerges in the discourse, and not from formal, a priori principles: "If one can speak of a statement, it is because a sentence (a proposition) figures at a definite point, with a specific position, in an enunciative network, that extends beyond it." (Foucault 1972:99)

Symbolic network approaches build from the idea that symbols derive meaning from their structural location in a web (Carley 1994; Edelmann and Mohr 2018; Mohr 1998), but there are diverse approaches to measure the relatedness of symbols to compose this web (Leifeld 2017). Some approaches start from handcoding symbols into broader units, while some rely on machine learning approaches (Mohr and Bogdanov 2013). Some approaches construct a conceptual network as a one mode graph indicating which concept is connected to others via semantic links (Carley 1994), while other approaches aim at transposing narratives into temporal networks where narrated events are linked in a directed one mode graph (Bearman and Stovel 2000).

A particularly promising approach from the perspective of integrating symbolic and social relations is a two-mode network approach to represent the duality of social and cultural structures. Ronald Breiger, a proponent of network duality in social networks (Breiger 1974) proposes to think in terms of duality of actors and actions or actors and their opinions (Breiger 2000; Pattison and Breiger 2002). The duality idea is central to the works of John Mohr in mapping symbolic positions in social policy (Mohr 1994; Mohr and Duquenne 1997) and university discourse (Mohr and Lee 2000).

The goal of symbolic network approaches is to uncover repeated regularities, by clustering individual symbols into genres, themes, topics, or frames (Mohr 1998; Rawlings and Mohr 2017). Once such emergent cultural structures are uncovered, the next task is to reconnect them to the realm of social action, where frames are used in interactions (Eliasoph and Lichterman 2003).

\section{Rejoining symbolic and social relations}

The network analytic study of culture have proven to be a useful tool in relational approaches to take action and interaction into account, beyond mapping symbolic structures (Edelmann and Mohr 2018), in parallel to broader trends in network analysis to expand from formalist empirism to relational theorization (Erikson 2016). Symbolic networks are mapped to help understand conflictual relations among political actors (Fuhse et al. 2020) or building ties of support (McLean 2007). 
The most prevalent mode of connecting symbolic structures with social relations in the political field is by envisioning a framing contest. Pierre Bourdieu's approach to linguistic power in the political field is to envision competing agents who offer symbolic structures - political products defining the line between thinkable and un-thinkable - for ordinary citizens to choose among (Bourdieu 1991). In a similar fashion, the literature on frame alignment imagines framing entrepreneurs, seeking to combine symbolic elements in novel ways, in hope of resonating with the way the audience thinks in a market of competing framings (Benford 1993; Snow 2004; Snow et al. 1986; Snow and Benford 2000).

The framing contest perspective of connecting symbolic and social relations generated valuable insight into forms and determinants of symbolic action: The relevant actor when one focuses on discourse is often an organization or group, rather than an individual (Eliasoph and Lichterman 2003). Actors can bridge, amplify, extend, transform, or blend existing frames seeking alignment with a broader constituency (Snow et al. 1986; Werner and Cornelissen 2014). Framing capacity is influenced by differential resource endowments of actors (Auyero 2002; Polletta et al. 2011), and external events can also serve as resources as they trigger shifts in collective sensemaking (Maitlis and Christianson 2014).

While the framing contest approach has proven to be useful in connecting symbolic structures and social action, it has missed the interactive, reactional element in discourse (Steinberg 1998, 1999): While framing is a perspective that aims to understand how power is generated from discourse, its entrepreneurial metaphor (with actors being frame producers facing a crowd of potential frame consumers) does not help understand how discourse producers mutually adjust their framings as they attempt to overpower each other (Breiger 2000; Schultz and Breiger 2010; Stevenson and Greenberg 2000).

\section{From framing contest to robust action}

There is a rich literature of discourse as an arena of strategic interaction beyond framing contest approaches. Charles Tilly analyzed contentious gatherings in Britain from the late eighteenth and early nineteenth century mapping how actors (political groupings) made claims and instigated attacks on one another, with claim making on the parliament emerging as a novel strategy (Tilly 1997). On the surface, actors are presenting coherent messages to a public, but coherence emerges in chaotic networks of discursive struggles (Krinsky and Mische 2013; Tilly and Wood 2017), and power and status is attained in this chaotic network, rather than in the subsequent transmission of coherence to constituents.

But how do actors gain status in a chaotic interaction, and how can we capture that moment by jointly analyzing cultural structures and interactions? The answer to this question is formulated in models and conceptions of robust action. In a survey of robust action perspectives, Ferraro and coauthors found that a common elements include heterogenous actors deploying multivocal discourses, while they 
keep a space open for experimentative action. Bringing robust action to a discourse context, we see that it is the flexibility of the frames used in interaction that provides the room for actors to explore positions that can dominate others (Gibson 2003, 2005). Robust actors avoid betraying their strategy by acting in opaque ways (Bothner, Smith, and White 2010; Padgett and Ansell 1993), and seize the moment when they have a reasonable chance to occupy a dominant position in the discourse (Gibson 2000).

A drawback of robust action approaches is that several central concepts are difficult top operationalize (such as opaqueness, ambiguity, seizing the moment, or betraying strategy). One approach that offers clear latches for operationalization is that of local action ${ }^{4}$ by Eric Leifer (Leifer 1983, 1988, 1991, 1992). Leifer considers strategic interaction in the face of a public, making his ideas highly applicable for political discourse : "The analysis centers on the dyad (actors A and B), with a »public« in the background" (Leifer 1988:886). Both parties in this dyad of actors aim at occupying a role, or social position that dominates the other. However, once the ambition of actor A becomes clear to actor B, she can occupy a position that dominates A. Hence both parties need to be opaque about the position they intend to occupy, and this opaqueness is achieved by local action: action without an aim to occupy a dominant position, but rather action with the aim to elicit more interaction, and hence to buy opportunities to read the intentions of the opposing party.

We use a dynamic two mode network approach to chart the local action dynamics of political discourse. We use a blockmodel approach to map positions and frames in the discourse. Our model of discourse dynamics is that political actors use positions from disconnected frames as local action. When an opportunity arises, they formulate a position where previously unconnected frames are connected. Our approach is different from the perspective of a framing contest. A framing contest approach would expect that political actors formulate their best position without hesitation, as they would expect this position to have the most traction with constituents. From the perspective of local action, coming forward with a unified master frame involves risk: a successful critique of that frame leaves political actors defeated.

In our case of postsocialist economic policy discourse political actors seek to occupy the role of the "one who defines the new economic system". This role claim can fail. Government political actors can be successfully put into a role of a failed government by the opposition, if the new rules they define can be framed by the opposition as a crisis. In this case the government can be depicted as leading the economy to the wrong path. By successfully framing a crisis, the opposition can claim the role of the potential new government that will cure the crisis and realize the end of transition. The opposition can also fail in framing a

\footnotetext{
${ }^{4}$ While local action is a conceptualization or robust action more generally, it would be clearer to refer to "local action and role clam" as a conception of robust action. The local action perspective is useful especially because it separates two components of robust action: exploratory local action and the decisive moment of role claim, when fruits of explorations are reaped.
} 
crisis. It can be depicted as destructive and merely power-hungry by the government side.

Discourse actors cannot afford to remain silent, as giving up the floor in political discourse equals to being defeated (Fairclough 2013; Schröter and Taylor 2018; Steinberg 1999; Thornborrow 2016). In the local action mode of interaction, the interest of actors is not silencing their opponents, but rather to see them switch through their discourse positions. When it comes to claiming a role - attempting to occupy a dominant discourse position - the interest of an actor is to silence their opponents.

\section{Hypotheses of local action dynamics}

We translate the idea of local action to hypotheses of discourse dynamics, that provide the opportunity for a strong test of the ideas of framing contest and local action. The first hypothesis is a weak one, in the sense that it considers amounts of speech acts in various discourse positions, regardless of the actor that is taking that position, and regardless of features of the actor taking the position. In a framing contest framework, we would not expect the frequency of discourse positions to differ from expected in a short temporal proximity of one another, as discovering alignment with preferences of a constituency is a longer-term process:

H1, weak hypothesis of local action dynamics in political discourse: We expect that the prevalence of discourse positions significantly differ from expected in the relevant temporal window following other positions.

While this first hypothesis might help test the presence of a local action dynamics in general, more specific hypotheses are needed to take actors and other controls into account. The idea of local action concerns adjustments made by actors (in either shifting among their discourse positions in local action, or occupying a dominant position at the right moment). Our proposition is that political actors use disconnected frames until they see the opportunity to connect them into a unified frame (occupy a position with multiple frames). Thus we introduce two specific hypotheses to test within-actor adjustments:

$\mathrm{H} 2$, strong hypothesis of local action: Actors will alter their positions as a function of the frequency of a particular position taken by others in a preceding time window, controlling for the frequency of other positions taken, and controlling for observed and unobserved heterogeneity at the political actor level.

The second aspect of local action dynamics is that at the right moment, after sufficient exploration of the behavioral portfolio of the opponent, a role claim is made, or in the case of political discourse, an attempt is made to occupy a dominant position. We expect that a dominant position will be one that is multivocal: a position spanning many frames (Emirbayer and Mische 1998; Emirbayer and Sheller 1998; Padgett and Ansell 1993). 
H3, strong hypothesis of role claim: Actors will reduce their number of speech acts as a function of the frequency of the dominant position taken by others in a preceding time window, controlling for the frequency of other positions taken, and controlling for observed and unobserved heterogeneity at the political actor level.

We now introduce the case of political discourse where we intend to test these hypotheses of robust action in discourse.

\section{The case of economic policy discourse, Hungary 1997}

We test hypotheses of local action dynamics in political discourse using a case of high-stakes political struggle, that brought about a discourse innovation of government actors that silenced the opposition. We discuss two aspects of selecting our case: specifying the general outline of the discourse we study, and the specific demarcation of the boundaries of our case. The general location of our case is Hungary, early 1997. This period can first of all be characterized by deep uncertainties regarding the shapes, rules and solidity of the economic and social system. Eight years after the political collapse of socialism it was still far from certain what shape a new (probably capitalist) economy will take, and when it will be consolidated. With the initial enthusiasm and self-confidence of hundred-day programs far behind, the everyday experience of the economy was shaped by repeated measures of austerity paired by a deep transitory recession.

The discourse on economic policy was characterized by deep entrenchment of government and opposition, with the leftist government defending restriction measures and the right wing opposition habitually rejecting them, but none of them were in a position to offer visions of the system emerging. It was only in the spring of 1997 when a new opportunity first opened up for outlining such visions, an opportunity to discursively end the period of transition. One of the key moments of this change was when the signs of economic growth first became evident. This happened at the end of the first quarter on 1997, at the end of March.

The specific boundaries of our case in time contain this first shift of the discourse towards defining the new economy. We analyze the economic policy discourse from the $1^{\text {st }}$ of March to the $30^{\text {th }}$ of June 1997. Beyond setting the longitudinal boundaries of our case horizontal boundaries needed to be defined as well. We analyze at the economic policy discourse that centers on consolidation, stabilization of a new economic-societal order.

\section{Data and methods}

We have collected all articles from the three most important Hungarian newspapers at the time that mentioned economic policy, its social consequences or the results of stabilization. in our period: from March 1, 1997 to June 30, 1997. 
In the first round we separated the discourse centered on stabilization from similar discourses, such as the discourse of privatization, globalization or public finances reform. In many cases we find statements from several discourses in one article, so we followed two basic principles in our selection. First we selected articles according to the most represented discourse in them. Second, in the case of articles or interviews where the actors tried to touch as many issues as they could, we selected the statements concerned with economic policy. We narrowed our population of articles in two rounds, finally gaining 620 articles.

In the second round we coded the statements. We distinguished statements and utterances. We defined utterance as the empirically observable part of text. We define statements to be the common content of similar utterances. In an iterative process the material was read first to define the main aspects of defining statements, second to define statements. The texts were re-coded repeatedly until the system of statements was sensitive enough to reproduce large portion of utterances. At this point the material was coded by these, now crystallized system of statements.

We started with 8632 utterances from 620 articles and 1400 statements (that is types of utterances) were identified with the initial qualitative coding process. To be able to identify the patterns in the discursive field we further reduced this statement set. In the final set of codes (after excluding statements with a frequency of utterances less than 5 and merging similar statements) we coded 180 statements that covered $79 \%$ of the whole discourse (we were able to classify 6822 utterances out of the 8632).

We then demarcated speech acts as occasions when one actor speaks in a newspaper. A speech act usually equals to an article. However, there were some occasions when there were two actors speaking in an article - we have separated these to become two speech acts. In the end the final dataset included 759 speech acts.

\section{Blockmodel of frames and positions}

The first step in our analytic strategy is to map frames and positions. We cluster statements into frames and speech acts into positions based on patterns of ties among them, taking a two-mode blockmodeling approach by structural equivalence: If two statements are mostly used together (or are mostly omitted together) then we see them to be structurally equivalent. A typical network blockmodel builds from a one-mode network (White, Boorman, and Breiger 1976), and has recently been extended to consider two mode networks as well (Doreian, Batagelj, and Ferligoj 2004). In our case there are two modes to consider separately: The structural equivalence blockmodel of one mode (statements) is independent from the blockmodel on the other mode (speech acts). Statements can be used (or avoided) together in many ways in various positions of the discourse. 
We Pearson's product-moment correlation as a measure of structural similarity of statement and position profiles, minimizing the effects of differences in statement or speech act centrality ${ }^{5}$. After computing the correlations of the structural profiles among the 180 statements and among the 759 positions we have used three clustering algorithms (CONCOR, complete link hierarchical clustering and average link hierarchical clustering) to find blocks of statements and blocks of speech acts with typical patterns. The eight-cluster solution of CONCOR for statements and the nine-cluster solution of CONCOR for speech acts were the best interpretable. We compared the eight and nine cluster solutions of the other two methods to the CONCOR blockings (see appendix $A$ for fit statistics). Based on fit and interpretation CONCOR seemed to be the best choice for both the statement and speech act partitioning.
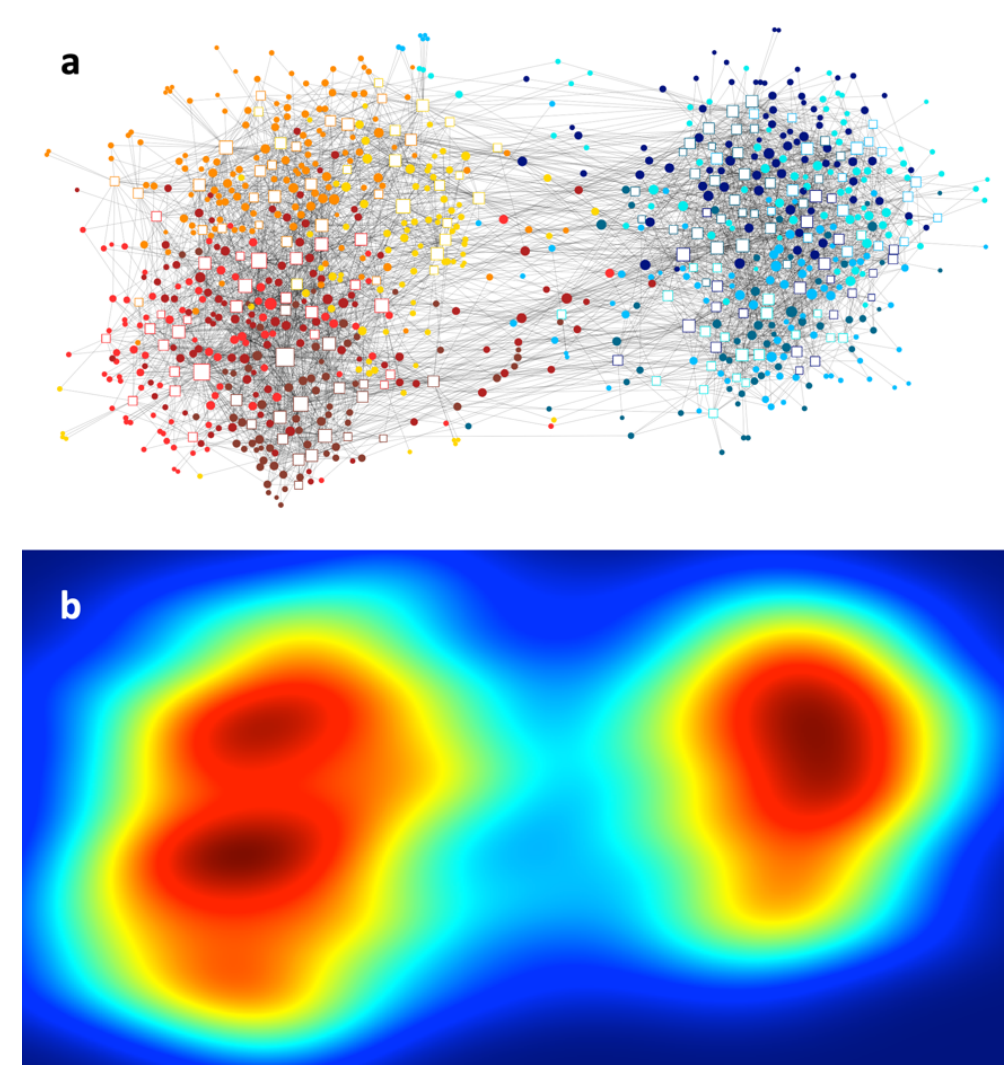

Figure 1: Two-mode network (Panel "a") and node density heatmap (Panel "b") of statements mentioned in speech acts. On Panel "a" filled disks represent speech acts (colored according to nine position blocks), and open squares represent statements (colored according to eight frame blocks). Node sizes proportional to degree.

\footnotetext{
${ }^{5}$ The other common alternative measure of structural equivalence is Euclidean distance that emphasizes centrality differences as well, beyond profile similarity. Correlation normalizes these centrality effects, and serves our purposes to identify frames and positions, where patterns of couse and omission of statements is the key, and not the popularity of statements, or the length of speech acts.
} 
There are two consequences of our fit statistics. One is that at the most fundamental level the expectation that there are rules to the discourse is probably true. The R squared for the statements and the speech acts blockmodel are 39\% and $29 \%$ respectively, that indicates a strong fit. The other consequence is that CONCOR provides the best fitting partition, which is probably due to the fact that the image of data inherent in the CONCOR algorithm maps well to our actual data. One basic feature of CONCOR is that it proceeds by binary splits: it divides the initial correlation matrix into two sub-matrices, and then subdivides these into two (if requested). The fact that CONCOR provides the best fitting solution probably corresponds to the fact that our data is characterized by binary divisions.

Figure 1 shows the two-mode network of the discourse, with speech acts and statements colored by their corresponding block memberships. There is a deep division between the government and the opposition side, marked by two clusters in the network that are especially visible by spatial node densities on panel $b$. If we had stopped at this two-by-two blockmodel, our image matrix would show government statements used in government speech acts and opposition statements used in opposition speech acts, while both sides omit the statements of the other side. Figure 2 shows the division trees on both modes of the network.

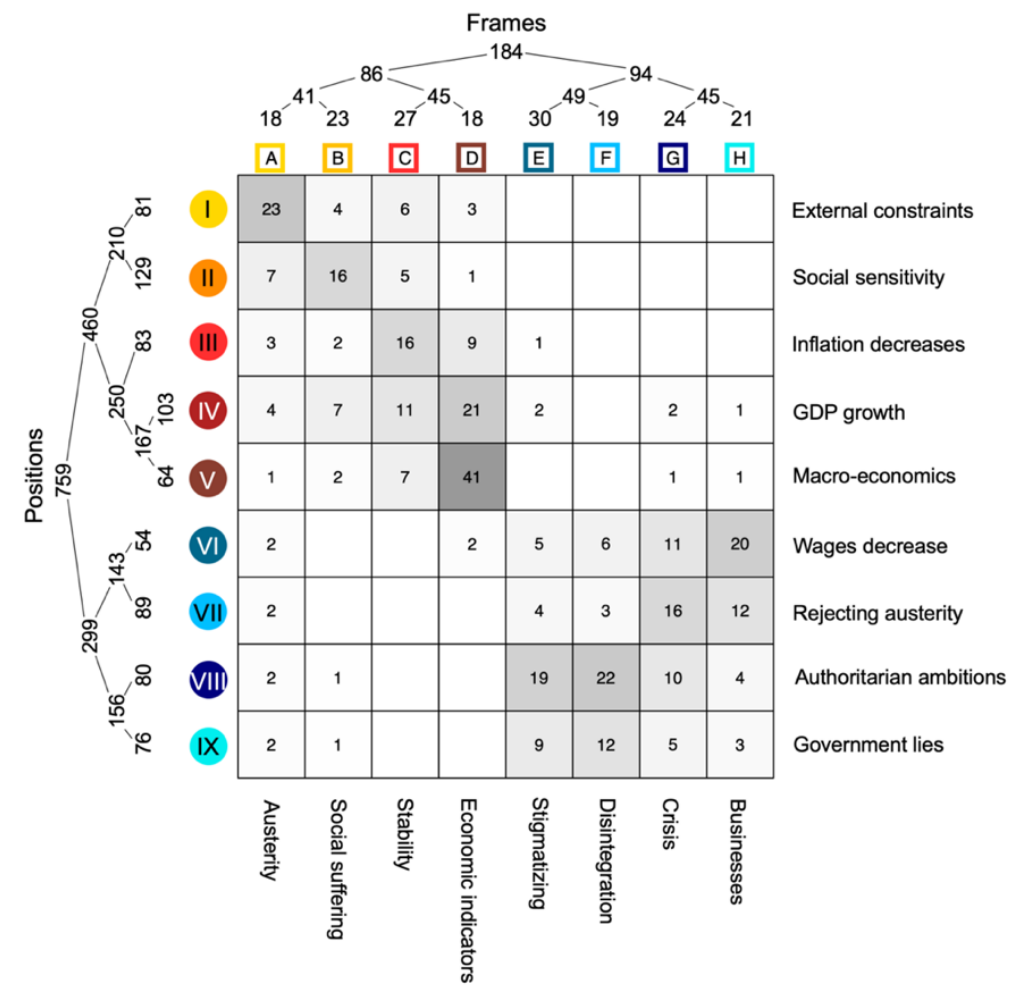

Figure 2: Two-mode CONCOR blockmodel with division trees for frames and positions. Table cells and shading show block densities in percentages.

Patterning in the data of interest to us goes beyond the two-block level: there are five government-side positions (building from four frames) and four oppositionside positions (also building from four frames). 
The first two government positions are about the (leftist) politics of austerity. The first government position, Position I: External constraints, builds from Frame A: Austerity. This position is about necessary and unavoidable restriction measures, pointing to external pressures on the government to introduce them. The second government position, Position II: Social sensitivity, builds from Frame B: Social suffering to acknowledge social suffering, and reassure the public that the government appreciates sacrifices made in a time of austerity, admitting only minor mistakes in economic policy.

There are three further government positions that are rooted in technocratic economist discourse. Position III: Inflation decreases is an attempt to translate economic indicators into positive news, centering on the decrease of price inflation, building mostly from two frames, Frame C: Stability about signs of a stabilized economy following the depths of postsocialist recession, and Frame D: Economic indicators - a purely technocratic, macro-economic frame with indicators on export, balances, GDP, production and investment numbers. Position IV: GDP growth is the dominant position of the government side, a true discourse innovation that helped link the most government-side frames in a highly effective way. This position connects macro-economic expert frames with stability and social suffering frames, to enable to government to project the end of austerity. Finally, Position V: Macro-economics is in a way the opposite of Position $I V$, as this is a single-frame macro-economics position.

The opposition side mirrors the government side, as their four positions can be divided into two more political, and two more expert positions. The first two, Position VI: Wages decrease, and Position VII Rejecting austerity are two expert positions. The first builds from the frames Frame H: Businesses and Frame G: Crisis, pointing out how the government neglects to support domestic businesses, and hence lets wages deteriorate further. The second position, on rejecting austerity builds from the same two frames, but emphasizes the crisis at the level of individual livelihoods that austerity had caused.

The opposition also operates with two positions that are about a direct attack on the government side. The first of these, Position VIII Authoritarian ambitions, is a vicious stigmatizing attack on the government, building from frames Frame E: Stigmatizing and Frame F: Disintegration. This position claims that the (leftist) government aims to return to communist dictatorship, and is fundamentally corrupt and morally rotten. A milder version of this position (building from mostly the same frames), Position IX: Government lies, accuses the government of falsifying economic indicators, questions the expertise and honesty of government members.

\section{Blockmodel robustness}

We tested the robustness of our blockmodel in multiple ways. On the onset we have coded the original utterances into 180 statements. To test robustness to this particular coding choice, we produced a new set of 120 statements by another 
round of recoding. We expect the statement (column) and the position (row) blockmodel structure computed with this new statement set to closely resemble the blockmodel solution we have obtained with 180 statements. We use Cohen's kappa to measure the strength of agreement between the original blocking and the new blocking, for both frames and positions. Cohen's kappa for frames equals 0.68 , for positions it equals 0.65 , indicating a strong agreement for both. (See more details on robustness in appendix $B$.)

Another robustness question concerns the effect of individual actors on the rules of the discourse. If discourse rules are external to actors, they should not change when one actor is excluded. We excluded the most central actors one by one and run our block-modeling method on these truncated datasets. (Note that excluding actors means the exclusion of speech act rows from our network matrix.) We expect the statement blockmodel structure to closely resemble the original blockmodel partition. Using Cohen's kappa again we see that the blockmodel is very robust to leaving out actors. For example, the statement blockmodel without the prime minister results in a kappa of 0.97 , the blockmodel without the leader of the opposition results in a kappa of 0.92 .

\section{Position multivocality}

We measured multivocality of positions by the extent to which they are composed of multiple positions. We used Shannon's entropy to capture position multivocality:

$$
H(X)=-\sum_{i=1}^{n} P\left(x_{i}\right) \log _{2} P\left(x_{i}\right),
$$

where $\mathrm{X}$ is the set of positions, with $i$ indicating either classes (either frames or individual statements), and $x_{i}$ is the number of speech act in a given class. We subtracted the minimal entropy value from all values for clearer readability (normalized entropy), and calculated entropy both for the distribution of speech acts along eight frames and along 180 statements. 


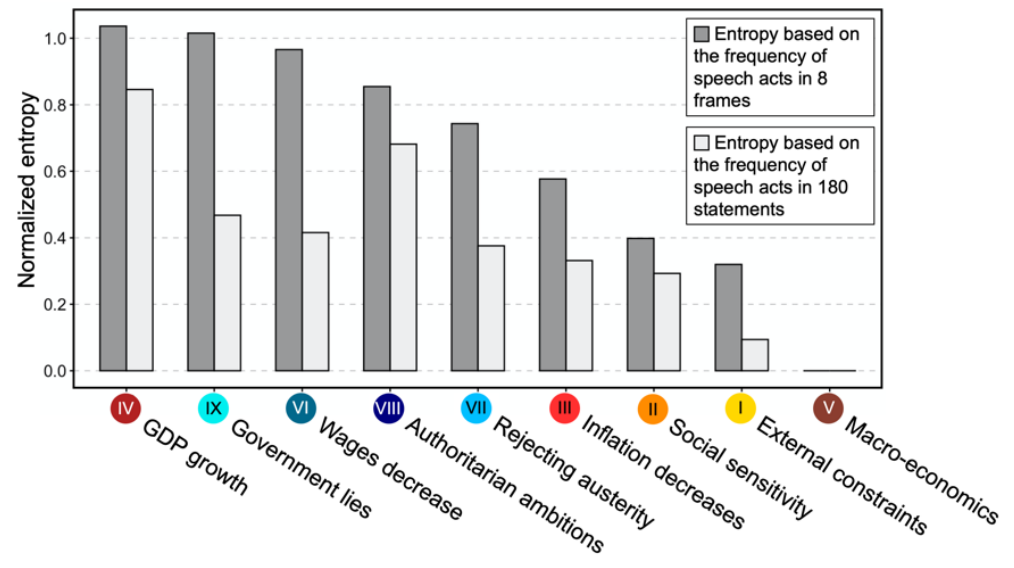

Figure 3: Multivocality of positions, measured by normalized entropy. Positions are sorted by entropy based on 8 frames.

Figure 3 shows normalized entropy measures for positions. It shows Position IV: GDP growth to be the most multivocal position, especially when we take both measures of entropy into account. GDP growth as a position spans all frames (both government and opposition frames) in the discourse, except the frame on disintegration. The second most multivocal position is the opposition talking about government lies - a position that reaches across stigmatizing and economic expert frames as well (for the need to specify who lies, and what they lie about). The least multivocal position (that we compare other positions to on this figure) is Position V: expert talk of macroeconomic indicators, that only builds from the macroeconomics frame.

\section{Relational discourse dynamics}

In the preceding section we have taken a network approach at the symbolic level of frames and positions. Now we turn to relational dynamics among actors, as the use these discourse positions. We have clustered each speech act into positions, and since speech acts are time-stamped (we know the day when they were made), we can trace the dynamics of positions take daily. However, a model that builds form the positions taken on a given day would not be a realistic model of discourse, as it would assume that a position taken on a given day disappears from the discourse by the next day. We assume that speech acts will be in the memory of the discourse for a while - probably somewhere between one and ten days. Ten days means almost two discourse weeks (as weekends are excluded for lack of newspaper printing), it is likely that a speech act decays from the discourse within two weeks. This memory of the discourse is probably a key element for local action dynamics: Once a position is taken, a speech act is made, it cannot be easily undone. Immediate forgetting of speech acts would grant infinite flexibility for politicians to experiment with an endless number of positions and stick to the one for which there is no dominant answer from the opposite side. 
We tested decay functions to identify the length and shape of discourse memory. One difficulty here is that we have no external measure for an accurate representation of discourse memory, so we have started from an assumption that our discourse is temporally patterned and formulated our analytic strategy in a way that enables us to reject this assumption. We have used four decay function shapes with decay lengths ranging from one to ten days (see appendix E). As a measure of "structured-ness" we used the product of the kurtosis and standard deviation of the day pattern correlation time series (see details in appendix $F$ ). Contrasted to 500 randomly rewired discourse datasets as a baseline, the seven day long moving average seemed to be the best estimator of discourse memory. The pattern produced by the seven days moving average was significantly more than what we would expect in a random discourse. This means that we can accept our hypothesis that the discourse is patterned; it is not just random noise without change.

We used the smoothing of our discourse to chart dynamics, and identify turning points, and presented our results on Figure 4. We identified seven phases, that explain $10 \%$ of the variance in the original (raw) discourse data and $50 \%$ of the variance in the smoothed discourse data (with the seven days moving average).

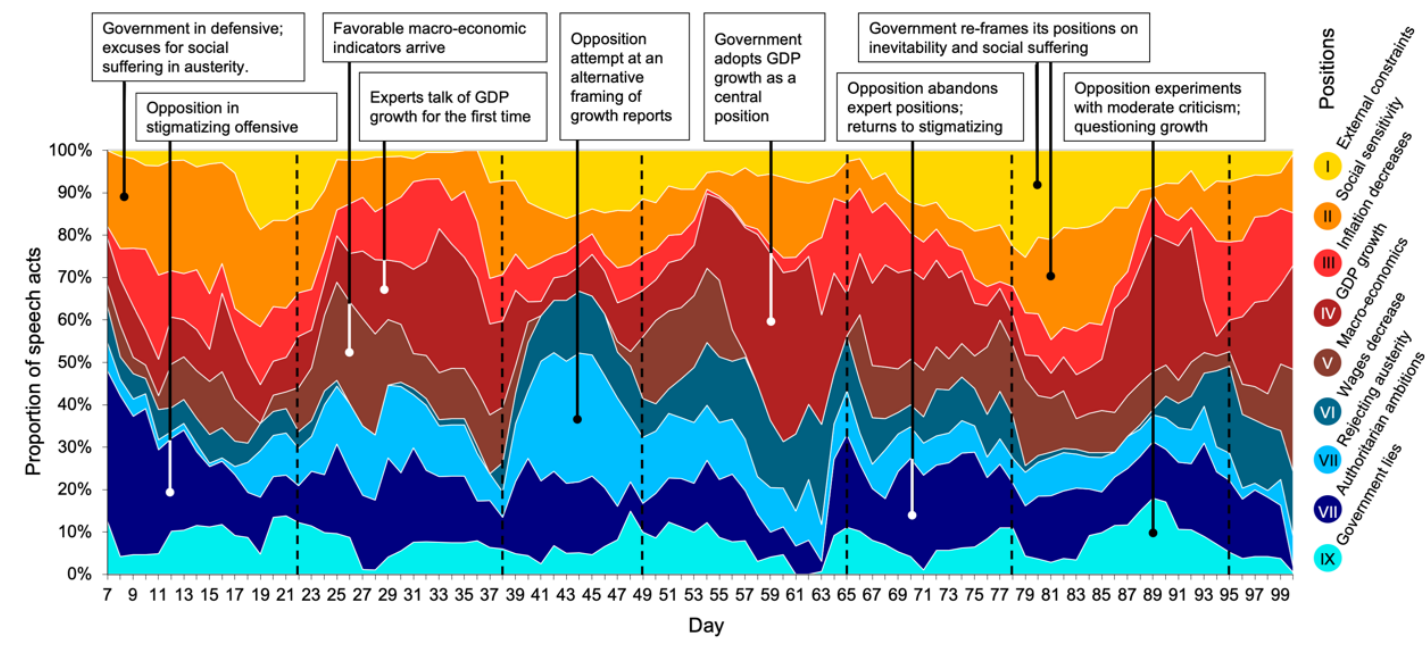

Figure 4: The discourse timeline after applying a seven day moving average. Proportions of speech acts in each of the nine positions shown. Phases are demarcated by dashed vertical lines.

In the first phase the major (left wing) government party is in a decidedly inferior role, acknowledging social suffering caused by austerity measures, while the opposition (FIDESZ party that recently shifted to the right) takes a strongly stigmatizing position, questioning the motives, moral integrity, and expertise of the government. The second phase sees the first instance when experts (economic think tanks and government experts) report GDP growth, for the first time over the past ten years, marked by a deep transitional recession. Over the third phase the first to react to this news is the opposition, trying to re-frame growth reports, rejecting macro-economic indicators in general, and claiming that employees and small businesses are struggling despite what macro-economic indicators say. 
The fourth phase sees the government recognizing the potential in GDP growth as a discursive position, and they adopt it widely. This leads over the fifth phase to the silencing of opposition positions on an alternative framing of an economic crisis. The sixth phase sees the opposition being defeated, practically abandoning all of their expert positions, resorting to stigmatizing. Subsequently the opposition shifts to a moderate (and not very effective) criticism centered on questioning the validity of growth reports. Meanwhile, over the remaining part of the discourse the government keeps talking of growth, and returns to mentioning the inevitability of austerity, now with a triumphant tone.

\section{Positions evoking and silencing other positions}

According to our first hypothesis, H1, we expect that the prevalence of discourse positions significantly differ from expected in the relevant temporal window following other positions. In our previous discussion on discourse dynamics, we found that a seven day moving average is the decay function that captures discourse dynamics the best. For each speech act we have created a seven days temporal neighborhood, containing the speech acts at least one and at most seven days after the given speech act. From the cross-tabulation of statement positions on a given day and statement positions at most seven days after it we can judge over- and under-representation in these temporal neighborhoods. We can reject our hypothesis if there were no significant differences between positions regarding what position came at most seven days after them. For this we have used a chi-square test. This test showed a strong significance $(p<0.001)$, so we can reject the null hypothesis to $\mathrm{H} 1$, that there is no difference between positions in what comes after them (and can not reject $\mathrm{H} 1$ ).

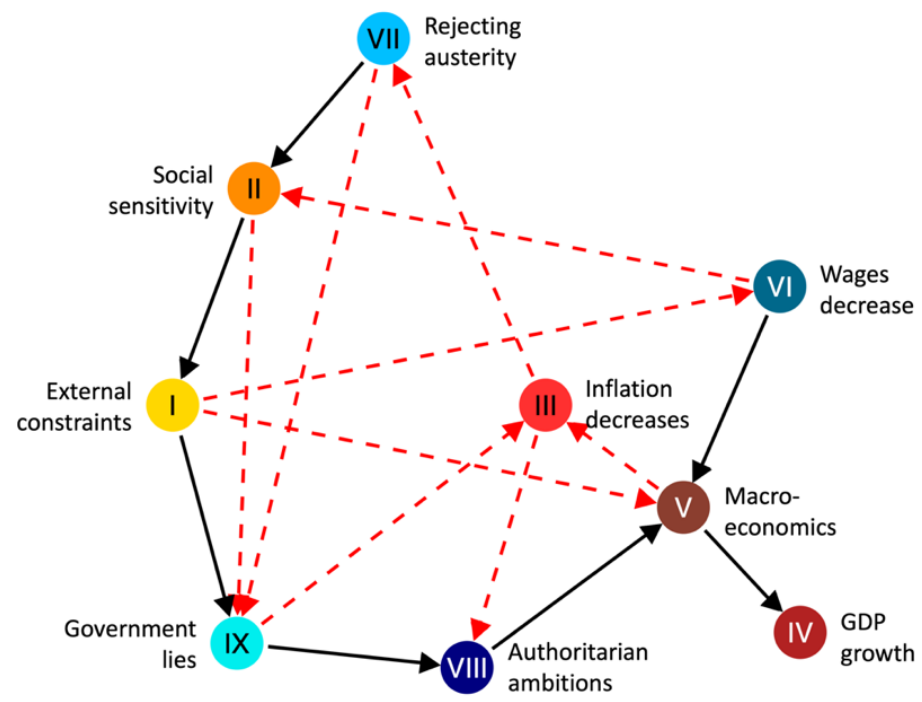

Figure 5: Over- and under-representation of positions at most seven days after other positions. Solid black arrows indicate significant over-representation measured by Pearson adjusted standardized residuals. Dashed red arrows indicate significant under-representation in the same manner. Arrows represent temporal ordering: The node the arrow points to is over-represented after the node from where the arrow originates. 
We present the weighted adjacency matrix of Pearson adjusted standardized residuals as a network graph on Figure 5. The peculiar feature of the figure is a chain of positions, in an almost perfect circle. Let us traverse along solid arrows of positive residuals, indicating that a certain position is significantly more likely to follow another, than we would expect by chance (with $\mathrm{p}<.05$ ).

The pattern on Figure 5 captures relational regularities that we have traced on Figure 4, when we followed the unfolding of our discourse as a struggle.

Traversing the graph on Figure 5 from the top, from Position VII: Rejecting austerity, typically used by opposition actors, we see that it evokes Position II: Social sensitivity, a defensive position of government side actors, emphasizing their awareness of social suffering. This position then evokes Position I: External constraints, a defensive justification of austerity by external constraints. As a response to this, we see an over-representation of Position IX: Government lies, where mostly opposition actors question the credibility of the government, followed by Position VIII: Authoritarian ambitions, a more radical, stigmatizing attack on the government. It seems that the fitting response to stigmatizing is a dose of dry macro-economics talk, as the next in our chain is Position V: Macroeconomics. This position is also overrepresented after Position VI: Wages decrease, the position that comes closest to an alternative economic expert talk to macro-economics on the opposition side. After macro-economics talk we see Position IV: GDP-growth overrepresented. No other position is overrepresented after talk of GDP-growth, just as Position III: Inflation decreases does not ring a bell for any other position to follow.

The temporal over- and under-representation relations between blocks proved to be fairly robust when we re-did the analysis for two halves of the data (for the first and the second fifty days of the discourse). The correlation of the table of the first half and the entire dataset was 0.72 , the correlation of the table from the second half was 0.90 , which means that the over- and under-representation relations are fairly constant over time. We have also counted sign reversals of residuals that were greater than one in absolute value. In the comparison of the first half to the whole dataset there were 3 reversals out of 25 occasions, while in the case of the second half there are 3 reversals out of 27 . This again shows the robustness of the observed relations between blocks.

\section{Re-orienting and silencing positions at the actor level}

With the weak hypothesis of local action dynamics, we tested whether the aggregate number of speech acts in a given position is followed by an amount of speech acts in other positions that is significantly above or below the expected frequency. The idea of local action requires a stronger test as well, when we consider actors in the discourse. For local action dynamics we should demonstrate shifts in the positions taken by particular actors, beyond showing aggregate trends. In this section we test two stronger hypotheses of local action: 
one about exploratory local action with shifting discourse positions, and one about role claim, when a dominant position is taken that silences discourse actors.

With our second hypothesis on exploratory local action, H2, we expect that actors will alter their positions as a function of the frequency of a particular position taken by others in a preceding time window, controlling for the frequency of other positions taken, and controlling for observed and unobserved heterogeneity at the political actor level. With our third hypothesis on role claim, H3, we expect that actors will reduce their number of speech acts as a function of the frequency of the dominant position taken by others in a preceding time window, controlling for the frequency of other positions taken, and controlling for observed and unobserved heterogeneity at the political actor level.

We test these hypotheses taking a pooled time series approach, where we make actor-days the unit of analysis. We coded 32 actor in the discourse, ranging from political parties and departments of government to research institutes and journalists. We are interested in approximating a quasi-experimental setting where we can measure within-actor effects of the increasing frequency of a particular position over a preceding time window (of seven days, from $t_{-1}$ to $t_{-7}$ ), as we keep relevant factors constant. First of all, we keep the frequency of other positions constant, to isolate the effect of the position in focus. We would also keep observable and unobservable actor level heterogeneity constant, to eliminate alternative hypotheses.

To test $\mathrm{H} 2$ on re-orienting positions, our dependent variable is position cosine distance, that measures the cosine distance between the vector of positions taken on the focal day $\left(\mathrm{t}_{0}\right)$ by the focal actor, and the vector of positions taken in the window of $t_{-1}$ to $t_{-7}$ by the same actor:

$$
d_{P W}=1-\frac{\sum_{i=1}^{n} P_{i} \cdot W_{i}}{\sqrt{\sum_{i=1}^{n} P_{i}^{2}} \cdot \sqrt{\sum_{i=1}^{n} W_{i}^{2}}},
$$

where $i$ indicates discourse positions from one to nine, $P$ records the frequency of speech acts the given actor made on the focal day in each of the nine positions, and $W$ records the frequency of speech acts made by the same actor over the preceding seven days in each of the nine positions. This variable ranges from zero if the actor did not change its speech by discourse positions at all, and one, when the actor shifted to using a complementary set of positions. Cosine distance had been used before to measure vector dissimilarity in symbolic spaces (De Vaan, Stark, and Vedres 2015; Evans 2010; Sohn 2001); we also use Euclidean distance to test the robustness of our findings.

To test $\mathrm{H} 3$ about silencing, our dependent variable is the number of speech acts on the focal day made by the focal actor.

Our key independent variables to test both $\mathrm{H} 2$ and $\mathrm{H} 3$ are the number of speech acts in each of the nine discourse positions made by actors other than the focal actor over the $t_{-1}$ to $t_{-7}$ temporal window, assuming that our dependent variables 
are measured on day $t_{0}$. Since such frequencies by positions are highly skewed variables, we log-transformed them by taking $\log _{10}(x+1)$, where $\mathrm{x}$ is a variable measuring frequency of speech acts in a given position. To avoid left-censoring, we analyze data from day 8 .

We introduced controls to test key alternative expectations. The most important are unobserved heterogeneity at the actor level in the tendency to shift discourse positions, the amount of speech acts, and trends in both changing positions and the amount of speech acts. Such heterogeneity is likely, stemming either from intrinsic actor motivations, or from motivations of newspaper editors in altering the coverage of various actors. Thus we include actor specific intercepts, and actor specific trends (interactions of actor dummies with the day trend).

We included control variables to capture actor importance and newspaper coverage. To measure actor importance, we included Page number (mean), that measures the mean of the page numbers across all newspapers where the focal actor appeared with a speech act on the focal day. We expect that actors deemed to be more important or interesting for newspapers will be covered on lower page numbers, and possibly be given more space (more statements). This differential attention by newspapers can influence both the extent of position re-orienting and the number of speech acts we see from actors. We also include the amount of coverage (number of speech acts logged) in each of the three major newspapers that covered the discourse, to control for particular political leaning in covering (or omitting) speech from actors, that again can influence the intensity of shifts and the amount of speech that we see.

\begin{tabular}{lrrrrr}
\hline \hline \multicolumn{1}{c}{ Variable } & $N$ & Mean & \multicolumn{1}{c}{ SD } & Min & \multicolumn{1}{c}{ Max } \\
\hline Position cosine distance * 100 & 314 & 68.10 & 38.28 & .00 & 100.00 \\
N of speech acts on $t_{0}$ & 2976 & 2.03 & 7.12 & .00 & 81.00 \\
Position blocks $\log (N+1)$ & & & & & \\
$\quad$ I: External constraints & 2976 & 1.47 & .50 & .00 & 2.10 \\
II: Social sensitivity & 2976 & 1.73 & .24 & .30 & 2.13 \\
III: Inflation decreases & 2976 & 1.56 & .31 & .00 & 1.98 \\
IV: GDP growth & 2976 & 1.79 & .26 & .00 & 2.26 \\
V: Macro-economics & 2976 & 1.38 & .66 & .00 & 2.04 \\
VI: Wages decrease & 2976 & 1.36 & .54 & .00 & 2.05 \\
VII: Rejecting austerity & 2976 & 1.55 & .45 & .00 & 2.32 \\
VIII: Authoritarian ambitions & 2976 & 1.83 & .24 & .00 & 2.25 \\
IX: Government lies & 2976 & 1.48 & .36 & .00 & 2.00 \\
Day & 2976 & 54.00 & 26.85 & 8.00 & 100.00 \\
Page number (mean) & 2976 & 16.11 & 9.66 & 1.00 & 26.00 \\
Coverage in Paper 1 (log) & 2976 & .29 & .52 & .00 & 2.08 \\
Coverage in Paper 2 (log) & 2976 & .30 & .53 & .00 & 1.85 \\
Coverage in Paper 3 (log) & 2976 & .28 & .51 & .00 & 2.18 \\
\hline \hline
\end{tabular}

Table 1: Descriptives. 


\begin{tabular}{|c|c|c|c|c|c|c|c|c|c|c|c|c|c|c|c|c|}
\hline & 1 & 2 & 3 & 4 & 5 & 6 & 7 & 8 & 9 & 10 & 11 & 12 & 13 & 14 & 15 & 16 \\
\hline 1. Position cosine distance $* 100$ & 1.000 & & & & & & & & & & & & & & & \\
\hline 2. N of speech acts on $t_{0}$ & -.075 & 1.000 & & & & & & & & & & & & & & \\
\hline 3. I: External constraints & -.034 & -.015 & 1.000 & & & & & & & & & & & & & \\
\hline 4. II: Social sensitivity & .076 & -.086 & .365 & 1.000 & & & & & & & & & & & & \\
\hline 5. III: Inflation decreases & .026 & -.127 & .020 & .083 & 1.000 & & & & & & & & & & & \\
\hline 6. IV: GDP growth & -.006 & -.059 & -.089 & -.120 & -.116 & 1.000 & & & & & & & & & & \\
\hline 7. V: Macro-economics & -.076 & .012 & -.080 & .067 & .029 & .236 & 1.000 & & & & & & & & & \\
\hline 8. VI: Wages decrease & .003 & .078 & .240 & -.136 & -.242 & -.154 & -.393 & 1.000 & & & & & & & & \\
\hline 9. VII: Rejecting austerity & -.050 & -.025 & .315 & -.016 & .018 & .123 & -.176 & .061 & 1.000 & & & & & & & \\
\hline 10. VIII: Authoritarian ambitions & -.120 & -.015 & .243 & .156 & .132 & .050 & .171 & .010 & .208 & 1.000 & & & & & & \\
\hline 11. IX: Government lies & .054 & -.031 & .214 & .020 & -.052 & .178 & .284 & .060 & .033 & .240 & 1.000 & & & & & \\
\hline 12. Day & .020 & -.026 & .373 & -.146 & .055 & .146 & .124 & .146 & .099 & .122 & .091 & 1.000 & & & & \\
\hline 13. Page number (mean) & .103 & .036 & -.054 & .022 & .120 & .043 & -.121 & -.054 & .036 & -.090 & -.060 & -.088 & 1.000 & & & \\
\hline 14. Coverage in Paper $1(\log )$ & -.112 & .101 & -.072 & -.139 & .020 & -.184 & .029 & -.198 & .001 & .000 & -.025 & .092 & -.029 & 1.000 & & \\
\hline 15. Coverage in Paper $2(\log )$ & -.072 & .141 & .012 & -.094 & -.012 & -.096 & -.002 & -.099 & .152 & -.002 & -.053 & .000 & -.017 & .147 & 1.000 & \\
\hline 16. Coverage in Paper $3(\log )$ & -.126 & .127 & .013 & -.224 & -.137 & -.042 & -.081 & .081 & .124 & .015 & -.011 & .059 & -.130 & .186 & .142 & 1.000 \\
\hline
\end{tabular}

Table 2: Correlations.

Results of our regression models are shown on Table 3. We have used ordinary least squares to estimate position cosine distance to test $\mathrm{H} 2$ and the number of speech acts to test $\mathrm{H} 3$. Correlations among independent variables were moderate (as displayed on Table 2), and multicollinearity was not a concern (all VIF levels were within conventional bounds, with the maximal VIF=3.79). 


\begin{tabular}{|c|c|c|c|c|}
\hline & \multicolumn{2}{|c|}{ Re-orienting (OLS) } & \multicolumn{2}{|c|}{ Silencing (OLS) } \\
\hline Dependent variable & \multicolumn{2}{|c|}{$\begin{array}{c}\text { Position cosine } \\
\text { distance*100 }\end{array}$} & \multicolumn{2}{|c|}{$\begin{array}{c}\mathrm{N} \text { of speech acts } \\
\text { on day } t_{0}\end{array}$} \\
\hline Units of analysis & \multicolumn{2}{|c|}{$\begin{array}{c}\text { Actor days, } \\
\mathrm{N} \text { of speech acts }>0\end{array}$} & \multicolumn{2}{|c|}{$\begin{array}{l}\text { Actor days, } \\
\text { all }\end{array}$} \\
\hline \multicolumn{5}{|l|}{ Independent variables } \\
\hline \multicolumn{5}{|l|}{ Position blocks } \\
\hline I: External constraints & -8.577 & $(6.660)$ & .413 & $(.356)$ \\
\hline II: Social sensitivity & $22.485 * *$ & $(10.432)$ & -.170 & $(.644)$ \\
\hline III: Inflation decreases & 4.698 & $(8.648)$ & -.272 & $(.453)$ \\
\hline IV: GDP growth & .570 & $(9.853)$ & $-1.169 * *$ & $(.579)$ \\
\hline V: Macro-economics & $-10.221 * *$ & $(4.387)$ & .245 & $(.241)$ \\
\hline VI: Wages decrease & -5.524 & $(4.944)$ & -.206 & $(.240)$ \\
\hline VII: Rejecting austerity & 1.592 & $(6.596)$ & .451 & $(.323)$ \\
\hline VIII: Authoritarian ambitions & $-22.364 * *$ & $(10.990)$ & .436 & $(.585)$ \\
\hline IX: Government lies & $17.065^{* *}$ & $(8.515)$ & -.259 & $(.406)$ \\
\hline Actor intercepts included & \multicolumn{2}{|c|}{ yes } & \multicolumn{2}{|c|}{ yes } \\
\hline Actor trends included & \multicolumn{2}{|c|}{ yes } & \multicolumn{2}{|c|}{ yes } \\
\hline Controls included & \multicolumn{2}{|c|}{ yes } & \multicolumn{2}{|c|}{ yes } \\
\hline Intercept & 52.749 & $(47.092)$ & 1.547 & $(2.577)$ \\
\hline$N$ & 314 & & 2,976 & \\
\hline Adj. $R$-sq. & .083 & & .128 & \\
\hline$R$-sq. change $e^{I}$ & .046 & & .006 & \\
\hline$A I C$ & 3,206 & & 19,799 & \\
\hline$B I C$ & 3,427 & & 20,261 & \\
\hline LR Test Chi-sq ${ }^{2}$ & $18.570 * *$ & & $22.231 * *$ & \\
\hline
\end{tabular}

Notes: Cells contain unstandardized coefficients; standard errors are in parentheses. 1: R-square improvement of reported model over model without position blocks.

2: Likelihood-ratio test compares the reported model to a model without position blocks.

$*: \mathrm{p} \leq 0.10 ; * * \mathrm{p} \leq 0.05 ; * * * \mathrm{p} \leq 0.01$

Table 3: Pooled time series OLS models of re-orienting and silencing.

Our hypotheses about local action, $\mathrm{H} 2$, expects that positions taken by other actors over a preceding window significantly predicts position change at the level of actors on the focal day. We reject $\mathrm{H} 2$ if none of the position block variables are significant predictors (or more precisely, significant positive predictors). Overall, the fit of the model is moderate, but the inclusion of position blocks significantly improves model fit. Our model on re-orienting shows that four of the nine position blocks are significant predictors of actor position change, and two of them are positive predictors: When other actors talk of social sensitivity (Position II.) or accuse the government of lying (Position IX.) we see significant change in positions at the actor level, controlling for observed and unobserved actor level heterogeneity. Thus we found support for $\mathrm{H} 2$ : the presence of local action dynamics in our discourse data.

Taking these results and our prior analysis of residuals together, we see that talk of social sensitivity was a position typically taken by government actors, to acknowledge suffering and sacrifice caused by austerity. Taking this position 
induced government side actors to shift to more talk of constraints and external pressures, and at the same time made it less likely for opposition actors to talk of government lies. When the opposition talked of government lies, government actors became less likely to talk about decreasing inflation, and opposition actors were more likely to switch to stigmatizing the government (Position VIII). Interestingly, this more radical stigmatizing talk (Position VIII) has a negative coefficient: it makes actors change their position less. It is probably not surprising that abstract and dry macro-economics talk (Position V) induces actors not to change their positions.

We tested the robustness of our models to alternative specifications, first replacing cosine distance by Euclidean distance in an OLS model, and using a Logit model with a dependent variable that equals one if cosine distance is greater than zero. Our findings were robust to changing the distance function, and in our Logit model only our finding about Position VIII have changed. (See Appendix B for details.)

Our hypothesis on role claim, H3, expects that the dominant position (Position IV: GDP-growth) silences actors, resulting in a significant reduction in the number of speech acts, even if controlling for observed and unobserved actor level heterogeneity. Our second model on Table 3 shows that we cannot reject this hypothesis, as increasing the frequency of Position IV on GDP-growth significantly decreases the number of speech acts, with all controls included. Although the fit and the improvement of fit with including blocks were moderate, the improvement of fit was statistically significant.

Our findings are robust to altering model specification: Beyond our OLS model reported above, we also used a Negative Binomial specification, and a Logit model (predicting any speech acts, as opposed to none). Both of these models showed a significant negative coefficient for Position IV. (See Appendix B for details.)

\section{Discussion and conclusions}

We have observed relational regularities in discourse dynamics on multiple levels of analysis. First, there are pronounced frames and positions in the discourse. Positions are usually centered on one frame, but some positions are more multivocal, and span multiple frames. On the government side a frame-spanning position is about GDP growth: the most multivocal (multi-frame, multi-statement) position in the discourse.

We have also observed these positions in use. The way in which positions evoke and silence others follow strong regularities, providing evidence for relationality in discourse. Political actors are not framing entrepreneurs waiting for a captive audience, but rather boxers in a ring waiting for an opportunity for a knock-out, while striving to avoid being silenced by their opponents. We found support for all three hypotheses of local action, and the evidence seems to be quire robust. 
Robust action seems to be a promising model for interpreting discourse dynamics. Robust action has strong roots in pragmatism, as it does not envision political actors as rational strategists, but rather as flexible and pragmatic opportunists. The pragmatism of robust action lies in the dual motivations of exploring the opponent while keeping the floor - avoiding to be silenced in front of the public. Exploration can lead to decisive action, exploitation of opportunities in the environment. For our leftist government actors, the opportunity arrived in the form of macro-economic reports from experts. The translation of such macroeconomic frames into political success was far from guaranteed: an attempt at a framing around decreasing inflation (Position III.) failed to silence the opposition, who had their own framing of economic indicators in their talk of decreasing wages (Position VI), that again failed to silence their opponents.

While we have found support for the idea of robust action as conceptualized in local action, there are several aspects of our findings that point to extensions of the concept of local action. First, the idea of exploratory local action as outlined by Leifer (Leifer 1988) envisions two actors engaged in a struggle to occupy a dominant role. In most cases of political discourse there are many actors, that raises interesting extensions of exploratory action to multi-party settings. The idea of "good cop-bad cop" setting for example is a triadic form of robust action (Brodt and Tuchinsky 2000), where exploratory local action is spread over partnering actors. The work of David Gibson offers interesting avenues of extending the local action analysis of discourse to multi-party settings by paying attention on how actors jump into the conversation by piggy-backing on others (Gibson 2000, 2003).

Second, the idea of exploratory local action emphasizes shifting positions in response to shifts seen from the alter, but does not discuss costs to these shifts. We have seen in our test of $\mathrm{H} 2$ on exploratory local action that while some positions induce larger position shifts, some positions induce staying with past positions. Take the radical stigmatizing position of the rightist opposition (Position VIII) as an example: it makes actors stick with what they were saying, as our regression results are showing. In a sense, changing your message in response to stigmatizing accusations can carry a risk: there are some such low levels of discourse quality from your opponents, that engaging with it would reflect badly on anyone.

Third, considering political discourse provides an opportunity to reflect on dominance and defeat as Leifer imagines it. Politicians will probably not remain silenced for good, after they are defeated by a multivocal discourse position that none of their positions can credibly dismantle. If we just follow our story further, in less than year following our data the opposition wins the election, and in 1998 Viktor Orban becomes prime minister for the first time, mostly thanks to toning down hist radical stigmatizing discourse, and adopting positions that center on a strong middle class reaping benefits of economic development (as opposed to letting multinational corporations benefit). In a sense, Orban found a way to 
create a multivocal position that resembled an expanded Position VI in this dataset.

Our findings have lessons beyond political discourse. Civic organizations in search of framings that resonate with constituencies should also take into account their exposure and vulnerability to adversaries, especially if their discourse positions are not multivocal. Studying hate speech and radical groups could be also understood by a local action approach. In the face of stigmatizing messages the best approach is probably no to alter discourse positions, until a multivocal robust response is found. 


\section{Appendix A: Measuring structure in dynamic discourse data}

There are one hundred days of discourse that we analyze, where each day can be characterized by the positions taken on that day. Positions are the row blocks of our data, the typical speech acts. There are nine positions identified, so for each day we can tell the amount of utterances made in each position. This means that we can think of the profile of a day, and that we can compare the profiles of two days. We have compared days by correlating their position profiles. A high positive correlation means that similar positions are taken or not taken in those two days. (We use correlation in order to focus on the proportions of positions and control for the difference in the overall number of positions taken in certain days.) A negative correlation between two days indicates a shift in the positions taken.

To characterize the shape of time we use a time series of correlations of the profiles of consecutive days. In case of no change over time this time series would consist of only plus ones. For random data the series of correlations would be a random oscillation between minus one and plus one. For a patterned process with phases and shifts the series of correlations would be close to plus one with occasional drops, smaller values indicating shifts in the proportion of positions. The correlation can be calculated between consecutive days and for days that are two or three days apart. Since shifts might occur over longer periods than one day, correlations two or three days apart should also be used.

To measure the extent to which our data is a patterned process we use the kurtosis and the standard deviation of the distribution of correlations. A high positive kurtosis indicates that the distribution has a high peak. For data with no change standard deviation is zero while kurtosis equals infinity. For a random walk standard deviation is high while kurtosis is low. For patterned process with phases and sudden shifts standard deviation is lower than for a random walk, while kurtosis is much higher. The product of kurtosis and standard deviation is our measure for pattern that is high when a process is patterned.

We employed four decay functions to the one hundred days of data, where each day is characterized by the number of utterances made in each of the nine position blocks. The four functions differ in their shape, that corresponds with the timing of faster and slower decay. The functions range from a fast initial decay and a slow final decay to a slow initial decay and a fast final decay. An extreme case of an early fast decay is raw data, where there is a maximal drop after the first day. The other extreme case for a late decay is moving average, where the weight stays equal for all days. The functions express a weight for the number of utterances of a given day as a function of how many days they are before the day in question. The formulas for the four functions are the following, ranging from fast initial decay (Function A) to the slowest initial decay( Function D), where $d$ is the given day before the day in focus and $D$ is the length of the decay in days:

Function A:

$$
f_{A}=\sqrt{\frac{1}{d}}
$$


Function B:

$$
f_{B}=1-\frac{d}{D}
$$

Function C:

$$
f_{C}=\log _{D+1}(D+1-d)
$$

Function D:

$$
f_{D}=1
$$

We have calculated all four functions for two to ten days lengths. The following figure shows the shapes of the decay functions for a ten-day decay.

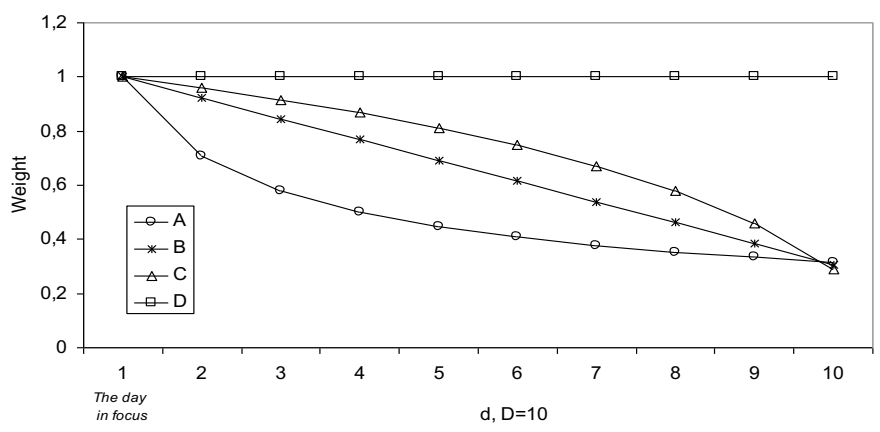

Figure 6: The shapes of the three decay functions used for the ten day long version. Day one is the day in question, day two is the day before etc., day ten is nine days before, the last day considered in the ten day weighted sum.

We calculated the amount of utterances in each of the nine blocks for each of the days with a set of decay functions. With each four function shapes a range of decay lengths from two to ten days is calculated. We based our choice out of these forty functions on the amount of patterning they produced. To judge patterning we have used the product of standard deviation and kurtosis.

One straightforward solution to choose the best decay function would be to pick the one with a maximal product of kurtosis and standard deviation. However, a strong caveat against using decay functions or moving averages is that they induce patterning in random data as well. To avoid artefactual solutions first we need to show that our decay functions perform better that they would for random data. Then we need to narrow our set of decay functions to those that induce significantly more pattern than do for random data. To accomplish this we have computed our patterns statistics for 500 random tables that 


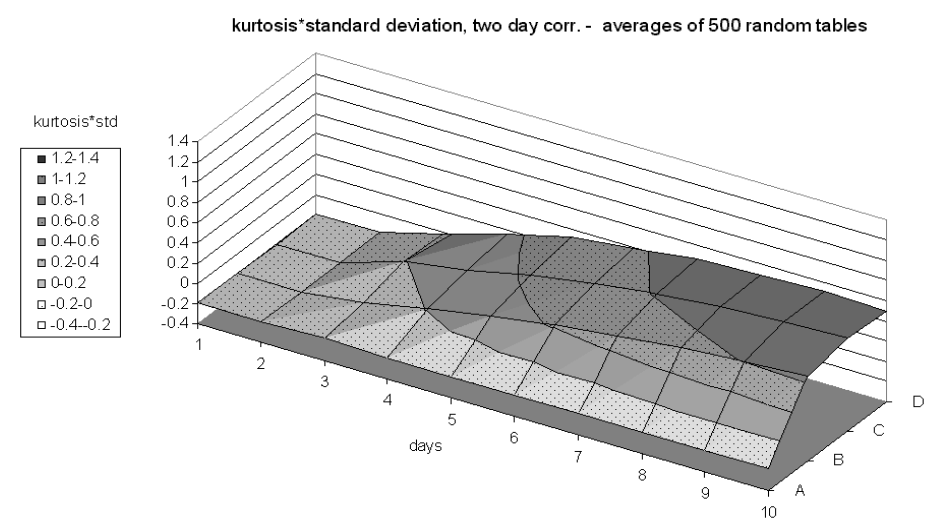

Figure 7: Patterning induced in random data. The product of kurtosis and standard deviation of two-day pattern correlations for the four decay functions (from A to D) with lengths from one to ten days. Averages from 500 random discourse data tables.

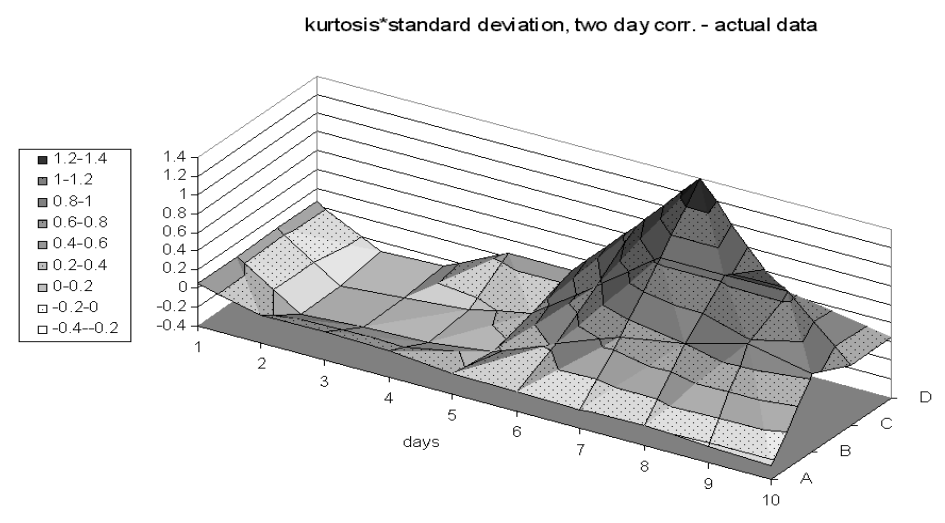

Figure 8: Patterning in the actual data. The product of kurtosis and standard deviation of two-day pattern correlations for the four decay functions (from A to D) with lengths from one to ten days.

We calculated the index of patterning (the product of kurtosis and standard deviation) for 500 random tables. Figure 7 shows that longer decay functions (610 days) and decay functions with a late drop (like function $C$ and D) induce patterning indeed in the random data. For each of the forty decay functions we can calculate the percentage out of the 500 random cases when that given function performed at least as good. A small percentage (5-10\%) means that the given function performed significantly better for our actual data than it had for random data. We calculated these significance indices for the one, two and three day correlations. In case of the one day correlation none of the functions reached the $10 \%$ significance levels. For the two day correlations (the correlations between a given day and the day two days before) there one significant function: the seven days moving average, with a 4,5\% significance. Figure 8 shows this as a high peak in the data at function $\mathrm{D}$, seven day length. So we choose this function to identify phases in the data. 


\section{Appendix B: Full model tables}

\begin{tabular}{|c|c|c|c|c|c|c|}
\hline & \multicolumn{2}{|c|}{$\begin{array}{l}\text { 1. Re-orienting (OLS), model } \\
\text { in main text }\end{array}$} & \multicolumn{2}{|c|}{$\begin{array}{l}\text { 2. Re-orienting (OLS), } \\
\text { Euclidean distance }\end{array}$} & \multicolumn{2}{|c|}{$\begin{array}{l}\text { 3. Re-orienting (Logit), cosine } \\
\text { distance }\end{array}$} \\
\hline Dependent variable & \multicolumn{2}{|c|}{ Position cosine distance* 100} & \multicolumn{2}{|c|}{$\begin{array}{l}\text { Position Euclidean } \\
\text { distance*100 }\end{array}$} & \multicolumn{2}{|c|}{$\begin{array}{l}\text { Position cosine } \\
\text { distance }>0\end{array}$} \\
\hline Units of analysis & \multicolumn{2}{|c|}{$\begin{array}{c}\text { Actor days, } \\
\mathrm{N} \text { of speech acts }>0\end{array}$} & \multicolumn{2}{|c|}{$\begin{array}{c}\text { Actor days, } \\
\mathrm{N} \text { of speech acts }>0\end{array}$} & \multicolumn{2}{|c|}{$\begin{array}{c}\text { Actor days, } \\
\mathrm{N} \text { of speech acts }>0\end{array}$} \\
\hline \multicolumn{7}{|l|}{ Independent variables } \\
\hline \multicolumn{7}{|l|}{ Position blocks } \\
\hline I: External constraints & -8.577 & $(6.660)$ & -12.864 & $(7.970)$ & -1.344 & $(1.353)$ \\
\hline II: Social sensitivity & $22.485^{* *}$ & $(10.432)$ & $26.948^{* *}$ & $(12.483)$ & $3.670^{*}$ & $(2.048)$ \\
\hline III: Inflation decreases & 4.698 & $(8.648)$ & 9.851 & $(10.348)$ & 2.272 & (1.394) \\
\hline IV: GDP growth & .570 & $(9.853)$ & 2.686 & $(11.790)$ & 1.568 & $(1.543)$ \\
\hline V: Macro-economics & $-10.221^{* *}$ & $(4.387)$ & $-11.688^{* *}$ & $(5.249)$ & $-1.184 *$ & $(.710)$ \\
\hline VI: Wages decrease & -5.524 & (4.944) & -6.385 & $(5.915)$ & -.879 & $(.912)$ \\
\hline VII: Rejecting austerity & 1.592 & $(6.596)$ & -1.409 & $(7.892)$ & $-4.461^{* *}$ & $(2.186)$ \\
\hline VIII: Authoritarian ambitions & $-22.364 * *$ & $(10.990)$ & $-26.202 * *$ & $(13.150)$ & -2.150 & $(2.253)$ \\
\hline IX: Government lies & $17.065^{* *}$ & $(8.515)$ & $19.126^{*}$ & $(10.189)$ & $5.560^{* *}$ & $(2.226)$ \\
\hline Actor intercepts included & \multicolumn{2}{|c|}{ yes } & \multicolumn{2}{|c|}{ yes } & \multicolumn{2}{|c|}{ yes } \\
\hline Actor trends included & \multicolumn{2}{|c|}{ yes } & \multicolumn{2}{|c|}{ yes } & \multicolumn{2}{|c|}{ yes } \\
\hline \multicolumn{7}{|l|}{ Controls } \\
\hline Day & .088 & $(.445)$ & .220 & $(.532)$ & 3.744 & (398.024) \\
\hline Page number (mean) & .557 & $(.764)$ & .453 & $(.914)$ & -.190 & $(.105)$ \\
\hline Coverage in Paper $1(\log )$ & -6.108 & $(5.410)$ & -4.844 & $(6.474)$ & $4.938^{* * *}$ & $(1.532)$ \\
\hline Coverage in Paper $2(\log )$ & -9.952 & $(6.230)$ & -12.069 & $(7.456)$ & $3.365^{* * *}$ & $(1.296)$ \\
\hline Coverage in Paper $3(\log )$ & -.548 & $(5.632)$ & .437 & $(6.740)$ & $3.140 * * *$ & $(1.131)$ \\
\hline Intercept " & 52.748 & $(47.092)$ & 1.547 & $(2.577)$ & -119.951 & (12087.290) \\
\hline$N$ & \multicolumn{2}{|l|}{314} & \multicolumn{2}{|l|}{314} & \multicolumn{2}{|l|}{314} \\
\hline Adj. $R$-sq. & \multicolumn{2}{|l|}{.083} & \multicolumn{2}{|l|}{.082} & \multicolumn{2}{|l|}{$.572^{3}$} \\
\hline$R$-sq. change ${ }^{l}$ & \multicolumn{2}{|l|}{.046} & \multicolumn{2}{|l|}{.047} & \multicolumn{2}{|l|}{.137} \\
\hline$A I C$ & \multicolumn{2}{|l|}{3,206} & \multicolumn{2}{|l|}{3,318} & \multicolumn{2}{|l|}{156} \\
\hline$B I C$ & \multicolumn{2}{|l|}{3,427} & 3,539 & & 288 & \\
\hline LR Test Chi-sq ${ }^{2}$ & $18.570^{* * *}$ & & $19.021^{* *}$ & & $24.980 * * *$ & \\
\hline
\end{tabular}

Notes: Cells contain unstandardized coefficients; standard errors are in parentheses. 1: R-square improvement of reported model over model without position blocks. 2: Likelihood-ratio test compares the reported model to a model without position blocks. 3: McFadden pseudo R-squared reported. *: $\mathrm{p} \leq 0.10 ; * * \mathrm{p} \leq 0.05 ; * *: \mathrm{p} \leq 0.01$

Table 4: Full model and alternative specifications for re-orienting positions. 


\begin{tabular}{|c|c|c|c|c|c|c|}
\hline & \multicolumn{2}{|c|}{$\begin{array}{l}\text { 1. Silencing (OLS), model in } \\
\text { main text }\end{array}$} & \multicolumn{2}{|c|}{$\begin{array}{l}\text { 2. Silencing (negative } \\
\text { binomial model) }\end{array}$} & \multicolumn{2}{|c|}{$\begin{array}{l}\text { 3. Silencing (Logit), any } \\
\text { speech acts }\end{array}$} \\
\hline Dependent variable & \multicolumn{2}{|c|}{$\begin{array}{c}\mathrm{N} \text { of speech acts on } \\
\text { day } t_{0}\end{array}$} & \multicolumn{2}{|c|}{$\begin{array}{c}\mathrm{N} \text { of speech acts on } \\
\text { day } t_{0}\end{array}$} & \multicolumn{2}{|c|}{$\begin{array}{c}\mathrm{N} \text { of speech acts on } \\
\text { day } t_{0}>0\end{array}$} \\
\hline Units of analysis & \multicolumn{2}{|c|}{ Actor days } & \multicolumn{2}{|c|}{ Actor days } & \multicolumn{2}{|c|}{ Actor days } \\
\hline \multicolumn{7}{|l|}{ Independent variables } \\
\hline \multicolumn{7}{|l|}{ Position blocks } \\
\hline I: External constraints & .413 & $(.356)$ & .429 & $(.429)$ & .284 & $(.166)$ \\
\hline II: Social sensitivity & -.170 & $(.644)$ & -.745 & $(.545)$ & -.278 & $(.287)$ \\
\hline III: Inflation decreases & -.272 & $(.453)$ & -.069 & $(.349)$ & .003 & $(.216)$ \\
\hline IV: GDP growth & $-1.169^{* *}$ & $(.579)$ & $-1.125^{* *}$ & $(.457)$ & $-.578^{* *}$ & $(.252)$ \\
\hline V: Macro-economics & .245 & $(.241)$ & $.367^{*}$ & $(.192)$ & .002 & $(.110)$ \\
\hline VI: Wages decrease & -.206 & $(.240)$ & -.261 & $(.235)$ & $-.275 * *$ & $(.127)$ \\
\hline VII: Rejecting austerity & .451 & $(.323)$ & $.647^{* * *}$ & $(.249)$ & .283 & $(.157)$ \\
\hline VIII: Authoritarian ambitions & .436 & $(.585)$ & -.342 & $(.471)$ & .092 & $(.268)$ \\
\hline IX: Government lies & -.259 & $(.406)$ & -.162 & $(.331)$ & -.049 & $(.185)$ \\
\hline Actor intercepts included & \multicolumn{2}{|c|}{ yes } & \multicolumn{2}{|c|}{ yes } & \multicolumn{2}{|c|}{ yes } \\
\hline Actor trends included & \multicolumn{2}{|c|}{ yes } & \multicolumn{2}{|c|}{ yes } & \multicolumn{2}{|c|}{ yes } \\
\hline \multicolumn{7}{|l|}{ Controls } \\
\hline Day & .006 & $(.026)$ & .002 & $(.013)$ & -.008 & $(.023)$ \\
\hline Page number (mean) & -.014 & $(.017)$ & .019 & $(.914)$ & .004 & $(.009)$ \\
\hline Coverage in Paper $1(\log )$ & $-.045^{* * *}$ & $(.015)$ & -.009 & $(.010)$ & -.070 & $(.146)$ \\
\hline Coverage in Paper $2(\log )$ & $-.046^{* * *}$ & $(.015)$ & $-.025 * *$ & $(.010)$ & -.233 & $(.152)$ \\
\hline Coverage in Paper $3(\log )$ & .009 & $(.013)$ & .007 & $(.009)$ & -.020 & $(.154)$ \\
\hline Intercept & 1.546 & $(2.576)$ & 1.058 & $(1.871)$ & -2.091 & $(1.567)$ \\
\hline$N$ & \multicolumn{2}{|l|}{2,976} & \multicolumn{2}{|l|}{2,976} & \multicolumn{2}{|l|}{2,976} \\
\hline Adj. $R$-sq. & \multicolumn{2}{|l|}{.128} & \multicolumn{2}{|l|}{$.047^{3}$} & \multicolumn{2}{|l|}{$.163^{3}$} \\
\hline$R$-sq. change ${ }^{l}$ & \multicolumn{2}{|l|}{.006} & \multicolumn{2}{|l|}{.002} & \multicolumn{2}{|l|}{.008} \\
\hline$A I C$ & \multicolumn{2}{|l|}{19,799} & \multicolumn{2}{|l|}{5,603} & \multicolumn{2}{|l|}{2,205} \\
\hline$B I C$ & \multicolumn{2}{|l|}{20,261} & 6,071 & & 2,667 & \\
\hline LR Test Chi-sq $q^{2}$ & $22.231^{* *}$ & & $19.130 * *$ & & $19.640 * *$ & \\
\hline
\end{tabular}

Table 5: Full model and alternative specifications for silencing. 


\section{References}

Auyero, Javier. 2002. "The Judge, the Cop, and the Queen of Carnival:

Ethnography, Storytelling, and the (Contested) Meanings of Protest."

Theory and Society 31(2):151-87. doi: 10.1023/A:1015039323606.

Bail, Christopher A. 2012. "The Fringe Effect: Civil Society Organizations and the Evolution of Media Discourse about Islam since the September 11th Attacks." American Sociological Review 77(6):855-79. doi: 10.1177/0003122412465743.

Bearman, Peter S., and Katherine Stovel. 2000. "Becoming a Nazi: A Model for Narrative Networks." Poetics 27(2-3):69-90. doi: 10.1016/S0304422X(99)00022-4.

Benford, Robert D. 1993. "Frame Disputes within the Nuclear Disarmament Movement." Social Forces 71(3):677-701. doi: 10.1093/sf/71.3.677.

Bothner, Matthew S., Edward Bishop Smith, and Harrison C. White. 2010. "A Model of Robust Positions in Social Networks." American Journal of Sociology 116(3):943-92. doi: 10.1086/658293.

Bourdieu, Pierre. 1991. Language and Symbolic Power. Reprint. Cambridge: Polity Press.

Breiger, Ronald L. 1974. "The Duality of Persons and Groups." Social Forces 53(2):181-90. doi: doi: 10.1093/sf/53.2.181.

Breiger, Ronald L. 2000. “A Tool Kit for Practice Theory.” Poetics 27(2-3):91115. doi: 10.1016/S0304-422X(99)00026-1.

Brodt, Susan E., and Marla Tuchinsky. 2000. "Working Together but in Opposition: An Examination of the 'Good-Cop/Bad-Cop' Negotiating Team Tactic.” Organizational Behavior and Human Decision Processes 81(2):155-77. doi: 10.1006/obhd.1999.2879.

Carley, Kathleen. 1994. "Extracting Culture through Textual Analysis." Poetics 22(4):291-312. doi: 10.1016/0304-422X(94)90011-6.

Cornelissen, Joep P., and Mirjam D. Werner. 2014. "Putting Framing in Perspective: A Review of Framing and Frame Analysis across the Management and Organizational Literature." Academy of Management Annals 8(1):181-235. doi: 10.5465/19416520.2014.875669.

De Sio, Lorenzo, and Till Weber. 2014. "Issue Yield: A Model of Party Strategy in Multidimensional Space." American Political Science Review 108(4):870-85. doi: 10.1017/S0003055414000379.

De Vaan, Mathijs, David Stark, and Balazs Vedres. 2015. "Game Changer: The Topology of Creativity.” American Journal of Sociology 120(4):1-51. 
De Vries, Catherine, and Sara Hobolt. 2020. "The Rise of Challenger Parties." Political Insight 11(3):16-19. doi: 10.1177/2041905820958817.

Dewulf, Art, Barbara Gray, Linda Putnam, Roy Lewicki, Noelle Aarts, Rene Bouwen, and Cees van Woerkum. 2009. "Disentangling Approaches to Framing in Conflict and Negotiation Research: A Meta-Paradigmatic Perspective." Human Relations 62(2):155-93. doi: 10.1177/0018726708100356.

van Dijk, Teun A. 1993. "Principles of Critical Discourse Analysis." Discourse \& Society 4(2):249-83. doi: 10.1177/0957926593004002006.

Doreian, Patrick, Vladimir Batagelj, and Anuška Ferligoj. 2004. "Generalized Blockmodeling of Two-Mode Network Data.” Social Networks 26(1):2953. doi: 10.1016/j.socnet.2004.01.002.

Edelmann, Achim, and John W. Mohr. 2018. "Formal Studies of Culture: Issues, Challenges, and Current Trends." Poetics 68:1-9. doi: 10.1016/j.poetic.2018.05.003.

Eliasoph, Nina, and Paul Lichterman. 2003. "Culture in Interaction." Source: American Journal of Sociology 108(4):735-94. doi: 10.1086/367920.

Emirbayer, M., and Ann Mische. 1998. "What Is Agency?" American Journal of Sociology 103(4):962-1023.

Emirbayer, Mustafa, and Jeff Goodwin. 1994. "Network Analysis, Culture, and the Problem of Agency." American Journal of Sociology 99(6):1411-54. doi: $10.1086 / 230450$.

Emirbayer, Mustafa, and Mimi Sheller. 1998. "Publics in History." Theory and Society 27(6):727-79.

Erikson, Emily. 2016. "Formalist and Relationalist Theory in Social Network Analysis." Sociological Theory 31(3):219-42.

Evans, James A. 2010. "Industry Induces Academic Science to Know Less about More." American Journal of Sociology 116(2):389-452. doi: $10.1086 / 653834$.

Fairclough, Norman. 2013. Critical Discourse Analysis: The Critical Study of Language. Hoboken: Taylor and Francis.

Ferraro, Fabrizio, Dror Etzion, and Joel Gehman. 2015. "Tackling Grand Challenges Pragmatically: Robust Action Revisited." Organization Studies 36(3):363-90. doi: 10.1177/0170840614563742.

Foucault, Michel. 1972. The Archaeology of Knowledge. London: Tavistock Publications. 
Fuhse, Jan A. 2016. "The Meaning Structure of Social Networks." Sociological Theory 27(1):51-73.

Fuhse, Jan A., Oscar Stuhler, Jan Riebling, and John Levi Martin. 2020. "Relating Social and Symbolic Relations in Quantitative Text Analysis. A Study of Parliamentary Discourse in the Weimar Republic.” Poetics 78:101363. doi: 10.1016/j.poetic.2019.04.004.

Gibson, David R. 2000. "Seizing the Moment: The Problem of Conversational Agency." Sociological Theory 18(3):368-82. doi: 10.1111/07352751.00106.

Gibson, David R. 2003. "Participation Shifts: Order and Differentiation in Group Conversation.” Social Forces 81(4):1335-80. doi: 10.1353/sof.2003.0055.

Gibson, David R. 2005. "Taking Turns and Talking Ties: Networks and Conversational Interaction." American Journal of Sociology 110(6):156197. doi: 10.1086/428689.

Gonos, George. 1977. "'Situation' versus 'Frame': The 'Interactionist' and the 'Structuralist' Analyses of Everyday Life." American Sociological Review 42(6):854. doi: 10.2307/2094572.

Green-Pedersen, Christoffer. 2019. The Reshaping of West European Party Politics: Agenda-Setting and Party Competition in Comparative Perspective. First edition. Oxford: Oxford University Press.

Hobolt, Sara B., and James Tilley. 2016. "Fleeing the Centre: The Rise of Challenger Parties in the Aftermath of the Euro Crisis." West European Politics 39(5):971-91. doi: 10.1080/01402382.2016.1181871.

Kaplan, Sarah. 2008. "Framing Contests: Strategy Making Under Uncertainty." Organization Science 19(5):729-52. doi: 10.1287/orsc.1070.0340.

Koopmans, Ruud, and Susan Olzak. 2004. "Discursive Opportunities and the Evolution of Right-Wing Violence in Germany." American Journal of Sociology 110(1):198-230. doi: 10.1086/386271.

Krebs, Ronald R., and Patrick Thaddeus Jackson. 2007. "Twisting Tongues and Twisting Arms: The Power of Political Rhetoric." European Journal of International Relations 13(1):35-66. doi: 10.1177/1354066107074284.

Krinsky, John, and Ann Mische. 2013. "Formations and Formalisms: Charles Tilly and the Paradox of the Actor." Annual Review of Sociology 39(1):126. doi: 10.1146/annurev-soc-071312-145547.

Leifeld, Philip. 2017. "Discourse Network Analysis.” Pp. 301-26 in The Oxford handbook of political networks, edited by J. N. Victor, A. H. Montgomery, and M. Lubell. Oxford University Press. 
Leifer, Eric M. 1983. Robust Action: Generating Joint Outcomes in Social Relationships. (Unpublished dissertation). Harvard University, Cambridge, MA.

Leifer, Eric M. 1988. "Interaction Preludes to Role Setting: Exploratory Local Action.” American Sociological Review 53(6):865-78.

Leifer, Eric M. 1991. Actors as Observers: A Theory of Skill in Social Relationships. New York: Garland.

Leifer, Eric M. 1992. "Denying the Data: Learning from the Accomplished Sciences.” Sociological Forum 7(2):283-99.

Maitlis, Sally, and Marlys Christianson. 2014. "Sensemaking in Organizations: Taking Stock and Moving Forward." Academy of Management Annals 8(1):57-125. doi: 10.5465/19416520.2014.873177.

McFarland, Daniel A. 2004. "Resistance as a Social Drama: A Study of ChangeOriented Encounters." American Journal of Sociology 109(6):1249-1318. doi: $10.1086 / 381913$.

McLean, Paul. 2007. The Art of the Network: Strategic Interaction and Patronage in Renaissance Florence. Durham [N.C.]: Duke University Press.

Meguid, Bonnie M. 2005. "Competition between Unequals: The Role of Mainstream Party Strategy in Niche Party Success." The American Political Science Review 99(3):347-59.

Mische, Ann, and Philippa Pattison. 2000. Composing a Civic Arena: Publics, Projects, and Social Settings. Vol. 27.

Mohr, John W. 1994. "Soldiers, Mothers, Tramps and Others: Discourse Roles in the 1907 New York City Charity Directory.” Poetics 22(4):327-57. doi: 10.1016/0304-422X(94)90013-2.

Mohr, John W. 1998. "Measuring Meaning Structures." Annual Review of Sociology 24(1):345-70. doi: doi:10.1146/annurev.soc.24.1.345.

Mohr, John W., and Petko Bogdanov. 2013. "Introduction-Topic Models: What They Are and Why They Matter." Poetics 41(6):545-69. doi: 10.1016/j.poetic.2013.10.001.

Mohr, John W., and Vincent Duquenne. 1997. "The Duality of Culture and Practice: Poverty Relief in New York City, 1888-1917.” Theory and Society 26(2/3):305-56.

Mohr, John W., and Helene K. Lee. 2000. "From Affirmative Action to Outreach: Discourse Shifts at the University of California." Poetics 28(1):47-71. doi: 10.1016/S0304-422X(00)00024-3. 
Nelson, Thomas E., and Donald R. Kinder. 1996. "Issue Frames and GroupCentrism in American Public Opinion." Journal of Politics 58(4):1055-78. doi: $10.2307 / 2960149$.

Padgett, John, and Christopher Ansell. 1993. "Robust Action and the Rise of the Medici, 1400-1434." American Journal of Sociology 98(6):1259-1319.

Pattison, Philippa E., and Ronald L. Breiger. 2002. "Lattices and Dimensional Representations: Matrix Decompositions and Ordering Structures." Social Networks 24(4):423-44. doi: 10.1016/S0378-8733(02)00015-1.

Polletta, Francesca, Pang Ching Bobby Chen, Beth Gharrity Gardner, and Alice Motes. 2011. "The Sociology of Storytelling." Annual Review of Sociology 37(1):109-30. doi: 10.1146/annurev-soc-081309-150106.

Rawlings, Craig, and John Mohr. 2017. Four Ways to Measure Culture: Social Science, Hermeneutics, and the Cultural Turn. Vol. 1. edited by J. C. Alexander, R. N. Jacobs, and P. Smith. Oxford University Press.

Schmelzer, Matthias. 2016. The Hegemony of Growth: The OECD and the Making of the Economic Growth Paradigm. Cambridge: Cambridge University Press.

Schröter, Melani, and Charlotte Taylor, eds. 2018. Exploring Silence and Absence in Discourse. Cham: Springer International Publishing.

Schultz, Jennifer, and Ronald L. Breiger. 2010. "The Strength of Weak Culture." Poetics 38(6):610-24. doi: 10.1016/j.poetic.2010.09.002.

Sniderman, Paul M., and Sean M. Theriault. 2004. "The Structure of Political Argument and the Logic of Issue Framing." Pp. 133-65 in Studies in Public Opinion: Attitudes, Nonattitudes, Measurement Error, and Change, edited by W. E. Saris and P. M. Sniderman. Princeton, NJ: Princeton University Press.

Snow, David A. 2004. "Framing Processes, Ideology, and Discursive Fields." Pp. 380-412 in The Blackwell companion to social movements. Vol. 1, edited by D. A. Snow, Soule, Sarah A, and Kriesi, Hanspeter. Wiley Online Library.

Snow, David A., and Robert D. Benford. 2000. "Framing Processes and Social Movements: An Overview and Assessment." Annual Review of Sociology 26(1974):611-39. doi: 10.1146/annurev.soc.26.1.611.

Snow, David A., E. Burke Rochford, Steven K. Worden, and Robert D. Benford. 1986. "Frame Alignment Processes, Micromobilization, and Movement Participation." American Sociological Review 51(4):464. doi: $10.2307 / 2095581$. 
Sohn, Min-Woong. 2001. "Distance and Cosine Measures of Niche Overlap." Social Networks 23(2):141-65. doi: 10.1016/S0378-8733(01)00039-9.

Steinberg, Marc W. 1998. "Tilting the Frame: Considerations of Collective Action Framing from a Discursive Turn." Theory and Society 27(6):845-72. doi: 10.1023/a:1006975321345.

Steinberg, Marc W. 1999. "The Talk and Back Talk of Collective Action: A Dialogic Analysis of Repertoires of Discourse among Nineteenth-Century English Cotton Spinners." American Journal of Sociology 105(3):736-80. doi: $10.1086 / 210359$.

Stevenson, William B., and Danna Greenberg. 2000. "Agency and Social Networks: Strategies of Action in a Social Structure of Position, Opposition, and Opportunity." Administrative Science Quarterly 45(4):651. doi: 10.2307/2667015.

Thornborrow, Joanna. 2016. Power Talk: Language and Interaction in Institutional Discourse. New York, NY: Routledge.

Tilly, Charles. 1997. "Parliamentarization of Popular Contention in Great Britain, 1758-1834." Theory and Society 26(2/3):245-73.

Tilly, Charles, and Lesley J. Wood. 2017. Social Movements, 1768-2008. Taylor and Francis.

Vasi, Ion Bogdan, Edward T. Walker, John S. Johnson, and Hui Fen Tan. 2015. " No Fracking Way!' Documentary Film, Discursive Opportunity, and Local Opposition against Hydraulic Fracturing in the United States, 2010 to 2013." American Sociological Review 80(5):934-59. doi: $10.1177 / 0003122415598534$.

Wacquant, Loïc J. D. 1995. "Pugs at Work: Bodily Capital and Bodily Labour among Professional Boxers." Body \& Society 1(1):65-93. doi: $10.1177 / 1357034 X 95001001005$.

Werner, Mirjam D., and Joep P. Cornelissen. 2014. "Framing the Change: Switching and Blending Frames and Their Role in Instigating Institutional Change." Organization Studies 35(10):1449-72. doi: 10.1177/0170840614539314.

White, Harrison C. 2008. Identity and Control: How Social Formations Emerge. 2nd ed. Princeton: Princeton University Press.

White, Harrison C., Scott A. Boorman, and Ronald L. Breiger. 1976. "Social Structure from Multiple Networks. I. Blockmodels of Roles and Positions." American Journal of Sociology 81(4):730-80. 